\title{
The influences of boredom proneness, public self-consciousness, and dressing style on internet shopping
}

\author{
Hye-Jung Park ${ }^{\dagger}$ \\ Dept. of Consilience, Korea Polytechnic University, Korea \\ 지루함, 공적 자의식, 스타일 지향성이 인터넷 구매에 미치는 영향 \\ 박 혜 정 ${ }^{\dagger}$ \\ 한국산업기술대학교 지식융합학부
}

\begin{abstract}
The purpose of this study is to identify the influences of psychological variables and fashion-related psychological variables on purchasing fashion items on the Internet. Boredom proneness and public self-consciousness were selected as psychological variables, and dressing style was selected as a fashion-related psychological variable. It was hypothesized that boredom proneness and public self-consciousness not only influence the purchasing frequency of fashion items on the Internet directly, but also indirectly through dressing style. Data were gathered by surveying university students in Seoul using convenience sampling. Two hundred and eighty-six questionnaires were used in the statistical analysis. SPSS was used for exploratory factor analysis, and AMOS was used for hypothesized relationship testing. The factor analysis of boredom proneness revealed five dimensions, "helplessness," "affective response," "lack of internal stimulation," "lack of external stimulation," and "perception of time." The factor analysis of public self-consciousness revealed two dimensions, "appearance-consciousness" and "styleconsciousness," and the factor analysis of dressing style revealed one dimension. The overall fit of the hypothesized model suggests that the model fits the data well. The hypothesized relationship test proved that boredom proneness and public self-consciousness influence the purchasing frequency of fashion items on the Internet indirectly through dressing style. The results implicate effective strategies for Internet shopping malls and suggestions for future study.
\end{abstract}

Keywords: boredom proneness(지루함), public self-consciousness(공적 자의식), dressing style(스타일지향성), internet shopping(인터넷 구매)

\section{Introduction}

인터넷 쇼핑몰의 성장으로 인해 소비자의 패션제 품 구매에 대한 이해를 제시하는 연구들이 다수 진 행되었다. 대부분의 연구들은 패션 인터넷 쇼핑몰의 특성이나 쇼핑몰을 이용하는 소비자 특성을 밝히고,
그 결과를 바탕으로 하여 효과적인 마케 팅 전략을 제시하고 있다. 구체적으로 쇼핑몰의 특성 중에서 인터넷 쇼핑몰의 구매나 만족도에 영향을 주는 쇼 핑몰의 자극요인 등을 밝히거나, 소비자의 특성 중 에서 쇼핑을 이끄는 소비자의 쇼핑성향, 쇼핑가치 또는 심리적 특성인 충동구매와 혁신성향을 밝히고

Received 18 August 2015, revised 14 October 2015, accepted 15 October 2015.

+ Corresponding author (hpark@kpu.ac.kr) 
있다.

패션 인터넷 쇼핑몰의 특성에 대하여 $\mathrm{Na}$ and Suh (2007)는 제품구색, 결재 및 보안, 로딩속도, 고객서 비스, 제품정보, 판매촉진, 화면구성과 같은 쇼핑몰 의 특성이 감정적 요인을 통해 충동구매에 미치는 영향을 밝혔다. 쇼핑몰의 특성을 제품특성으로 제한 하여 실시한 연구로서 Hong, Lee, and $\mathrm{Ma}$ (2009)는 여성 소비자의 쇼핑가치, 구매만족도 및 재구매 의 도에 미치는 영향을 밝혔다. 최근에는 쇼핑몰의 특 성을 더 구체화하여 인터넷 쇼핑몰의 상호작용성이 구매행동에 미치는 영향을 밝힌 연구들(Lee, 2008; Park, 2008)이 있다.

패션 인터넷 쇼핑몰을 이용하는 소비자 특성을 밝 히는데 있어서 쇼핑성향을 밝히는 연구들 $(\mathrm{Ji}, 2013 \mathrm{a}$; $\mathrm{Na} \&$ Suh, 2007), 라이프 스타일 유형에 따른 특성 을 밝힌 연구(Kim, 2008), 의복관여와 인터넷 사용 의 영향을 밝힌 연구(Hwang, 2003)가 있다. 그러나 패션 인터넷 쇼핑몰을 이용하는 소비자에 대한 기 본적인 이해를 제시하기 위해서는 심리적 특성을 밝혀야 하지만, 소비자의 심리적 특성이 인터넷 구 매에 미치는 영향을 밝힌 연구는 대부분 충동구매 성향을 밝히는 연구들(Ji, 2013a, 2013b; Lee \& Kim, 2006; Park \& Koh, 2008)과 혁신성향을 밝히는 연구 들(Lee \& Kim, 2013; Lee, Park, \& Heo, 2002)이다. 쇼핑몰의 특성과 같은 전략 외에도 젊은 세대들의 심리적 특성인 지루함 성향과 과시적인 패션제품의 구매와 관련이 높은 공적 자의식이 구매를 이끌 수 있으나, 이를 밝히는 연구는 미흡하다. 따라서 본 연 구는 패션 인터넷 쇼핑몰을 이용하는 소비자의 심리 적 변수로서 지루함 성향과 공적 자의식 변수를 선정 하여 소비자에 대한 이해를 제시하고자 한다. 또한 인터넷에서의 패션제품 구매는 Hwang (2003)에 의 해 의복관여와 같은 패션관련 심리적 변수에 의해 영향을 받는 것으로 나타났으므로, 소비자의 심리적 변수 외에도 패션관련 심리적 변수인 스타일 지향 성(dressing style)을 선정하여 인터넷 구매에 미치는 영향을 밝히고자 한다.

Kim, Choi, and $\operatorname{Kim}(2007)$ 은 현실에서의 여가 공 간 및 프로그램 부족, 이용하기 편리하고 쉽게 만족 을 얻을 수 있는 가상공간의 장점, 인터넷을 위한 사 회기반시설의 확충, 정보기술 사용을 장려하는 사회
적 분위기 등이 대중의 심리적 특성과 맞물리면서 인터넷 이용률이 급격히 증가하고 있다고 하였다. 이처럼 사회환경적 요소뿐 아니라, 소비자의 심리적 특성에 의해 인터넷 이용률과 함께 인터넷 쇼핑몰 도 계속적으로 성장하고 있다고 할 수 있다. 그런데 Son(2014)은 많은 청소년들이 지루함과 씨름하고 있으며, 지루함을 달래기 위해 사이버 공간에서 시 간을 보내고 있다고 하였다. 이에 따라 본 연구는 젊 은 세대들의 심리적 특성인 지루함 성향으로 인해 손쉽게 인터넷 쇼핑몰 서핑과 구매를 할 것으로 보 고, 지루함을 인터넷 구매의 선행변수로 선정하였다. Boredom이란 용어가 국내 상담학이나 청소년학에서 '권태' 또는 '지루함'으로 번역되어 사용되고 있으 나, 소비자학에서 있어서 '싷증'으로 사용되고 있다. 본 연구에서는 '권태'와 ‘싫증'보다는 '지루함'이 적 절해 보여서 지루함으로 번역, 사용하고자 한다. 지 루함 성향이 소비에 미치는 영향에 대한 연구들이 해외에서는 활발히 전개되었다. 그러나 국내에서는 상 담학에서 성인의 권태성향에 대한 연구(Hong \& Lee, 2014), 청소년학에서 청소년기의 지루함 성향이 분 노에 미치는 연구들(Lim, 2010, 2014)과 게임중독에 미치는 연구들(Lim, 2015; Son, 2014)로서 상대적으 로 미흡하다. 또한 경영학으로서 해외에서는 조직행 동 관점에서 종업원의 지루함을 밝히는 연구들(Drory, 1982; Watt \& Hargis, 2010)이 있으며, 국내에서는 최근에 지루함을 싫증으로 번역한 브랜드 싷증에 대한 연구들(Jang \& Park, 2014; Park, Jang, \& Lee, 2014)이 있다. 패션에 대한 소비자 행동에 있어서 지루함 성향의 중요성은 Studak and Workman(2004) 와 Workman and Studak(2005)에 의해 제시되었다. Studak and Workman(2004)는 패션에 대한 혁신자, 의견선도자, 혁신적 커뮤니케이터, 추종자의 집단으 로 분류한 뒤, 지루함 성향에 대한 차이를 밝혔다. 그리고 Workman and Studak(2005)는 패션소비자 집단, 통제감(locus of control), 내재적 즐거움, 지루 함 극복(boredom coping)의 관계를 밝혔다. 본 연구 는 국내 의류학에서 지루함 성향이라는 새로운 변 수를 소개하여 패션스타일 지향성과 인터넷 패션제 품 구매행동에 미치는 영향을 밝히고자 한다.

자의식이란 개인의 주의를 내적이나 외적으로 두는 개인의 일관적인 성향인데(Mittal \& Balasubramanian, 
1987), 특히 주의를 외적으로 두는 공적 자의식은 타인들에게 우호적인 이미지와 관련된 소비자 행동 을 결정하는 중요한 요소로 고려된다(Workman \& Lee, 2011). Gould and Barak(1988)은 공적 자의식이 사회적으로 과시적인 제품에 대한 구매 행동에 영 향을 준다는 실증적으로 제시하였다. 패션제품은 대 표적인 과시적 제품이므로 공적 자의식이 인터넷에 서의 패션제품의 구매에 영향을 줄 것으로 보고, 공 적 자의식을 인터넷 구매의 선행변수로 선정하였다. 해외에서 다수의 연구들(Gould \& Barak, 1988; Miller, David, \& Rowold, 1982; Workman \& Lee, 2011)이 공적 자의식이 패션에 대한 행동에서 유의적인 영 향을 준다는 것을 밝혔다. 국내 소비자를 대상으로 도 공적 자의식이 의복행동에 영향을 준다는 것이 다 수의 연구들(Koh \& Kim, 1996; Lee, 2010a, 2010b; Park, 2015)에 의해 밝혀졌다. 따라서 공적 자의식은 패션관련 심리적 변수인 스타일 지향성과 인터넷에 서의 패션제품 구매에 영향을 미칠 것으로 보이므 로 이를 밝히고자 한다.

스타일 지향성은 패션에 대한 소비자 행동을 결 정하는 중요한 변수로 제시되고 있다. $\operatorname{Park}(2013)$ 은 Dressing style을 스타일 지향성으로 번역하여 사용 하면서, 스타일 지향성은 패션기업이 제시하는 스타 일을 소비자가 수용하는 것을 설명하기 때문에 중 요하다고 하였다. Park(2014)도 패션산업은 유행 트 렌드 아래 다양한 패션 스타일의 공존과 변화를 추 구하므로, 이에 대한 소비자 수용을 결정하는 패션 스타일 지향성을 이해하는 것이 중요하다고 하였다. 국내 소비자를 대상으로 스타일 지향성에 대한 이 해를 심리적 변수로 제시하는 유일한 연구로서, Park (2013)은 게인의심리적 변수인 신체적 외모, 물질 주의, 개성추구가 스타일 지향성에 유의한 영향을 준다는 것을 밝혔다. 이러한 심리적 변수들은 패션 제품 구매에 영향을 주는 변수들이므로, 스타일 지 향성은 인터넷 쇼핑몰이 제시하는 다양한 스타일의 패션제품 구매에 영향을 줄 것으로 보이므로 인터 넷 구매의 선행변수로 선정하였다.

본 연구는 인터넷 패션제품 구매의 선행변수로 심 리적 변수인 지루함, 공적 자의식과 패션관련 심리 적 변수인 스타일 지향성을 선정하여, 공적 자의식 과 지루함 성향이 인터넷 구매에 영향을 미치는 것
은 물론, 스타일지향성을 통해 인터넷 구매에 영향 을 미칠 것으로 보고, 이를 밝히고자 한다. 본 연구 의 결과는 급성장하는 패션 인터넷 쇼핑몰에서의 소비자에 대한 이해를 지루함 성향, 공적 자의식, 스 타일 지향성이라는 새로운 심리적 변수와 패션관련 심리적 변수로 제시한다는 것에 의의가 있다. 또한 이러한 이해를 바탕으로 인터넷 쇼핑몰의 마케터에 게 효과적인 마케팅 전략을 제시하고자 한다.

\section{Background}

\section{Boredom proneness}

Farmer and Sundberg(1986)는 지루함 성향은 개 인적인 특성으로 보고, 이를 측정하기 위한 척도를 개발, 제시하였다. 지루함이 약물 남용, 비만과 비비 만인의 식사, 직무불만족, 학생들의 무단결속과 관 련이 있음을 밝힌 선행연구들을 제시하면서 심리학 적으로 지루함은 광범위하고 중요한 문제로 인식되 고 있다고 하였다. 그리고 지루함 성향이 심리적 변 수들인 우울함, 절망, 감지된 노력(perceived effort), 외로움, 의욕상실 성향(amotivational orientation)과 정적 관련이 있는 반면, 삶의 만족과 자율성 성향 (autonomy orientation)과는 부정적 관련이 있음을 밝 혔다. Vodanovich and Kass(1990)는 선행연구들을 근 거로 Farmer and Sundberg (1986)의 지루함 성향을 5가 지 요인으로 지정하여 요인분석한 결과, 외부자극 (external stimulation), 내부자극(internal stimulation), 정 서적 반응(affective response), 시간 지각(perception of time), 억제(constraints)를 추출하였다. 외적 자극은 흥미로움, 변화, 도전에 대한 필요를 지각하는 문항 들로 구성되며, 내적 자극은 자신을 즐겁고 재미있 게 유지하는 것과 관련된 문항들로 구성된다. 정서 적 반응은 지루함에 대한 감정적 반응에 대한 문항 들로 구성되며, 시간 지각은 시간의 사용과 관련된 문항들로 구성된다. 억제는 참을성(patience), 불안정 함(restlessness)과 같은 기다림에 대한 개인의 반응 에 대한 문항들로 구성된다. 그리고 지루함 성향이 단일차원보다 다차원으로 개념화하는 것이 적합함 을 제시하였다.

지루함 성향에 대한 차원의 분류는 다양한 지루함 에 대한 상세한 평가를 가능하게 하므로(Vodanovich, 
Wallace, \& Kass, 2005), 5요인으로 구성된 Farmer and Sundberg(1986)의 척도를 사용하여 탐색적 요인분 석을 제시하는 것이 소비자의 지루함 성향에 대한 깊이 있는 이해를 제시할 수 있다. 또한 국내 소비자 를 대상으로 지루함 성향을 분석한 연구도 미흡할 뿐 아니라, Farmer and Sundberg(1986)의 척도를 이 용하여 지루함 성향을 분석한 연구도 없으므로 본 연구는 그들의 척도를 이용하여 측정한 지루함 성향 에 대해 탐색적 요인분석을 행하는데 의의가 있다. 국내 성인의 지루함 성향에 대한 연구(Hong \& Lee, 2014)와 청소년기의 지루함 성향에 대한 연구들 $(\mathrm{Lim}$, 2010; 2014; 2015)은 12문항으로 구성된 Vodanovich et al.(2005)의 단축형 척도를 사용하였다. 더욱이 Hong and Lee(2014)는 외적 자극 요인만을 지정하 여 분석에 사용하였으며, 그 외 연구들은 내적 자극 과 외적 자극요인의 두 요인으로 보고, 확인적 요인 분석을 실시하였다. 따라서 국내 연구로서는 본 연 구 결과가 유일할 뿐 아니라, 지루함 성향이 의류학 에서 새롭게 제시되는 변수이므로 본 연구는 지루 함 성향에 대한 요인분석 결과를 깊이 있게 논의하 고자 한다.

의류학에서 지루함 성향의 중요성은 Studak and Workman(2004)와 Workman and Studak(2005)에 의 해 제시되었는데, 그들 모두 Farmer and Sundberg (1986)의 척도를 사용하였다. Studak and Workman (2004)는 즐거운 쇼핑 환경이 소비자들의 부정적인 감정을 치료할 수 있기 때문에, 소비자를 유인한다 는 것을 지적하면서 지루함 성향과 패션 소비자 행 동의 관계를 밝히는 연구가 필요한데도 불구하고 미흡하다고 하였다. 그리고 그들은 패션에 대한 혁 신자, 의견선도자, 혁신적 커뮤니케이터, 추종자의 집단으로 분류한 뒤 집단에 따른 지루함 성향에 대 한 차이와 성별에 따른 지루함 성향의 차이를 밝혔 다. 패션 변화 주도자인 혁신자, 의견선도자, 혁신적 의사소통자는 자신을 즐겁게 하고, 즐길 수 있게 하 는 능력과 높은 수준의 가만히 있지 못함으로 인해 패션 추종자보다 지루함에 덜 민감하다는 것을 밝 히면서 지루함이 패션 소비자 행동에 영향을 준다 는 것을 실증적으로 제시하였다. 그리고 Workman and Studak(2005)는 변화 주도자 집단이 추종자 집 단보다 지루함 성향의 5 가지 차원인 외적 자극, 내
적 자극, 정서적 반응, 시간 지각, 억제에 대하여 낮 을 것이라고 보고 연구한 결과, 내적 자극과 정서적 반응에 대해서만 낮은 점수를 보였다. 따라서 본 연 구는 지루함 성향이 스타일 지향성에 부적 영향을 줄 것으로 본다.

$\operatorname{Son}(2014)$ 은 많은 국내 청소년들이 지루함을 느 끼고, 이를 달래기 위해 사이버 공간에서 시간을 보 내고 있다고 지적하였다. 따라서 본 연구는 젊은 세 대들의 심리적 특성인 지루함 성향이 사이버 공간에 서의 패션제품 구매빈도에 정적 영향을 줄 것으로 본다. 또한 지루함 성향이 충동성(impulsiveness)에 정적 영향을 준다는 것을 밝힌 Watt and Vodanovich (1992)에 의해서도 지루함에 의해 인터넷에서 패션 제품을 충동적으로 구매할 것으로 보인다.

\section{Public self-consciousness}

자의식이란 자기지각의 상황에서 관심의 대상을 자기 자신에게 두고자 하는 일관되고 지속적인 경 향이다(Park, 2015). Nystedt and Ljungberg(2002)는 자기중심적 주의(self-focused attention)가 심리학에서 다양한 접근을 하는데 있어서 가장 중요한 개념이라 고 하고, 자의식의 중요성을 강조하였다. Fenigstein, Scheier, and Buss(1975)는 자아에 대한 인식이 행동과 삶에 대한 다양한 다른 접근들 중에서 가장 핵심적인 개념이라고 보고, 자의식에 대한 개인차를 측정하는 도구를 개발, 제시하였다. Mittal and Balasubramanian (1987)은 최근 심리학에서 자의식의 특성이 개인의 행동을 결정하는데 중요한 역할을 한다는 것이 입 증되고 있다고 하였다.

Fenigstein et al.(1975)는 자의식을 ‘주의(attention) 를 내부나 외부로 향하게 하는 개인의 일관적인 성 향'이라고 정의하고, 사적 자의식과 공적 자의식, 사 회불안의 세 가지 차원으로 구성된다고 하였다. 공 적 자의식은 타인관점에서 바라본 '사회적 존재 (social object)로서의 자기에 대한 일반적 인식'이며, 사적 자의식은 '개인의 내적 감정, 사고에 주의를 기 울이는 것'을 말한다고 하였다. 사회적 불안(social anxiety)은 '타인의 존재에 대한 불편함'으로 정의하 였다. 그리고 공적 자의식, 사적 자의식이 자신에 주 의를 기울이는 것을 말하는 것에 비해, 사회적 불안 은 이러한 과정에 대한 반응을 말한다고 하였다. 예 
를 들면, 주의가 내적으로 향할 때 사람들은 무엇인 가에 불안하게 되므로, 자의식에 대한 부산물로서 사회적 불안이 나타난다고 하였다. 그리고 그들은 공적 자의식은 $\operatorname{Mead}(1934)$ 의 자아를 인식하는 것은 타인의 관점을 인식하게 될 때 자아를 인식한다는 개념과 관련이 있다고 하였다. 이러한 공적 자의식 은 타인들에게 우호적인 이미지와 관련된 소비자 행 동을 결정하는 중요한 요소로 고려되어서(Workman and Lee, 2011), 다수의 연구들이 공적 자의식을 밝 히고자 하였다.

공적 자의식이 높은 사람들은 다른 사람들과 함 께 하고, 자신들을 모니터링 하고자 하는 욕구가 강 하며(Klonsky \& Dutton, 1990), 특히 다른 사람에게 주는 인상에 관심을 가진다(Bushman, 1993). 따라서 공적 자의식이 높은 사람들은 타인에게 거부당하고 싶어 하지 않거나, 칭찬 받고 싶어 하는 승인욕구에 의해 대인행동이 좌우되므로(Jeon \& Yoo, 2011), 외 모관리와 이미지관리에 관심이 높아서 의복행동에 영향을 줄 것으로 보인다. 이에 대한 실증적 연구들 로서 미국 성인 소비자들 대상으로 Gould and Barak (1988)은 공적 자의식이 사회적으로 과시적인 소비 행동에 영향을 줄 뿐 아니라, 패션 혁신성과 패션 의 견선도력과 같은 소비자의 패션관련 특성에 영향을 준다는 것을 밝혔다. Workman \& Lee(2011)는 패션 혁 신성과 의견선도력에 따라 패션 변화 주도자(fashion change agents)와 패션 추종자 집단으로 분류한 후, 패션 변화 주도자 집단의 공적 자의식이 패션 추종 자 집단보다 높다는 것을 밝혔다. Miller et al.(1982) 은 공적 자의식이 패션 의견선도력, 의복 관심과 지 각된 패션성과 정적 관계가 있음을 밝혔다.

국내 소비자를 대상으로 외모관리 행동에 영향을 준다는 연구들(Hong, 2010; Lee, 2010b; Ryoo \& Yoo, 2007; Son, 2007, 2008)과 이미지관리 행동에 영향 을 준다는 연구(Jeon \& Yoo, 2011)가 있다. 또한 의 복행동에 영향을 준다는 것을 밝힌 다수의 연구들

(Koh \& Kim, 1996; Lee, 2010a, 2010b; Park, 2015) 이 있다. 자신의 외모에 대한 타인의 평가를 중요시 여기는 공적 자의식이 높은 사람들은 외모에 대한 사회문화적 가치를 내재화하며, 자신의 신체를 더 많이 감시하고 평가한 결과, 외모에 대해 많은 관심 을 갖고 신체적 아름다움과 외모를 관리한다(Jeon
\& Yoo, 2011). 또한 공적 자의식이 높은 소비자들은 자신을 사회적 대상으로 인식하여 사회문화 집단 내에서 주변 사람들과의 관계를 중시하며, 타인들의 자신에 대한 지각을 중시한다(Lee, 2010b). Lee(2010b) 는 공적 자의식이 높으면 신체적 외모와 패션관련 제품 구매 결정 시 다른 소비자 행동을 보일 것이라 고 보고, 여대생을 대상으로 연구한 결과, 공적 자의 식이 높을수록 외모관심 허영심과 외모자신감, 허영 심이 유의하게 높았으며, 브랜드의식이 높게 나타났 다. 또한 Lee(2010a)는 대학생을 대상으로 공적 자 의식이 높을수록 패션제품의 브랜드에 민감성이 높 다는 것을 밝혔다. $\operatorname{Park}(2015)$ 은 공적 자의식과 사 적 자의식에 따라 관심의 집중이 다르므로, 패스트 패션 태도와 관련이 있을 것으로 보고, 여고생을 대 상으로 연구한 결과, 패스트 패션 태도 유형에 따라 자의식과 화장행동이 다르다는 것을 밝혔다. 따라서 공적 자의식은 패션관련 심리적 변수인 스타일 지 향성과 인터넷에서의 패션제품 구매에 정적 영향을 미칠 것으로 보인다. 특히 자아 존줌감, 자기통제력, 가상공간에서의 자기 효능감으로 구성된 자의식이 성인의 인터넷 이용에 유의적인 영향력을 밝힌 $\mathrm{Kim}$ et al.(2007)에 의하면 공적 자의식이 인터넷 패션제 품 구매에 정적 영향을 줄 것으로 보인다.

\section{Dressing style}

패션의식은 '패션 트렌드 지향적인 소비자의 성향' (Nirmala \& Dewi, 2011)으로 정의된다. Wan, Youn, and Fang(2001)은 패션의식(fashion consciousness) 을 스타일 지향성, 물질주의, 신체적 외모, 개성추구 와 같은 다양한 심리적 특성을 포함하는 다차원으 로 제시하면서 스타일 지향성이라는 변수를 제시하 였다. Wan et al.(2001)이 제시한 스타일 지향성 변 수에 대하여 Park(2013)은 Gutman and Mills(1982) 의 패션성향의 한 요인인 '의복의 중요성(importance of being well dressed)'과 비슷하지만, 다음과 같은 점에서 다르다고 하였다. 의복의 중요성은 총체적으 로 삶에서 의복을 잘 입는 것에 대한 문항들만 포함 하고 있는데 비해, 패션스타일 지향성은 그 외에도 스타일 지향적 의복의 소유와 패션잡지를 통한 스 타일 인식에 대한 문항들을 포함하고 있어서 스타 일의 수용에 대한 이해를 제시하고 있다고 하였다. 
따라서 본 연구는 스타일 지향성을 패션에 있어서 스타일을 즐기고 수용하려는 성향으로 정의한다. 그 리고 변화 지향적인 패션산업에서의 소비자에 대한 이해를 제시할 수 있다고 보고 스타일 지향성을 인 터넷 구매행동의 선행변수로 선정하였다.

스타일 지향성과 Goldsmith and Hofacker(1991) 의 패션 혁신성의 차이는 수용 대상인 스타일에 있 다. 패션혁신성은 '새로운 패션지향적인 의복을 수 용하는 소비자의 성향'으로서 대상이 새로운 스타 일의 의복으로 한정하는데 비해, 스타일 지향성의 대상은 새로운 스타일을 포함하는 스타일 지향적인 모든 의복이다. 따라서 스타일 지향성은 패션 혁신 성보다 대상이 더 포괄적인 변수라고 할 수 있다. 따 라서 스타일 지향성은 새로운 스타일은 물론, 다양 한 스타일을 제시하는 인터넷 패션 쇼핑몰에서의 패션제품 구매에 정적 영향을 미칠 것으로 보인다.

Gould and Stern(1989)과 Wells and Tigert(1971) 는 패션의식을 단일차원 척도로 제시하였는데, 다수 의 연구들이 그들의 척도를 사용하였다. 그러나 Wan et al.(2001)은 패션의식을 패션 스타일 지향성, 물질 주의, 신체적 외모, 개성추구와 같은 다양한 심리적 특성을 포함하는 다차원으로 제시하고, 이를 실증적 으로 밝혔다. 특히 패션의식에 대한 설명력에 있어 서 스타일 지향성이 가장 컸으며, 다음으로 물질주 의, 신체적 외모, 개성추구 순서임을 밝혔다. 이러한 결과는 패션의식에 있어서 스타일 지향성이 중요하 다는 것을 의미한다. 그리고 Park(2014)은 Wan et al. (2001)의 다차원적인 패션의식을 이용하여 국내 대 학생을 대상으로 역할완화 소비가 패션의식에 미치 는 영향을 밝혔다. 연구결과, 역할완화 소비의 모든 차원들이 패션의식의 요인인 스타일 지향성에 유의 적인 영향을 미치는 것으로 나타났다. 그런데 패션 의식에 대한 요인분석 결과는 Wan et al.(2001)과 다 르게 나타났다. 물질주의 요인은 나타나지 않았으 며, 개성추구가 설명력이 가장 크고, 다음으로 스타 일 지향성과 신체적 외모의 순서로 나타났다. 그러나 개성추구와 스타일 지향성의 설명력 크기는 $22.87 \%$ 과 $22.77 \%$ 로서 차이가 아주 미미하게 나타났으므 로, 스타일 지향성 변수가 중요함을 실증적으로 제 시하였다고 할 수 있다.

다수의 연구들이 패션의식에 대한 이해를 제시하
기 위하여 다양한 심리적 변수와의 관련성을 밝혔 다. Kwon(1997)은 패션의식과 사회적 자기존중의 관계를 밝혔으며, $\operatorname{Casidy(2012)ㄴㅡㄴ~Big~} 5$ 성격요인들 에 따라 집단을 분류한 후, 집단에 따른 패션의식의 차이를 밝혔다. 그런데 패션의식보다 현재의 패션 소비자 행동에 대한 이해를 더 잘 제시하는 스타일 지향성에 유의한 영향을 주는 심리적 변수에 대한 이해를 제시하는 연구는 국내 대학생을 대상으로 한 Park(2013)이 있다. Park(2013)은 스타일 지향성 의 선행변수로서 개인의 심리적 변수인 신체적 외 모, 물질주의, 개성추구를 선정하였다. 개성 추구는 스타일 지향성에 직접적인 영향을 주었으며, 신체적 외모는 가격의식이라는 의복관련 변수를 통해 스타 일 지향성에 영향을 주는 것으로 나타났다. 따라서 본 연구는 스타일 지향성에 대한 심리적 이해를 제 시하기 위하여 지루함 성향과 공적 자의식이 스타 일 지향성에 미치는 영향을 밝히는 것은 물론, 스타 일 지향성이 인터넷 구매에 미치는 영향을 밝히고 자 한다.

\section{Methods}

\section{Research hypotheses}

본 연구는 급성장하고 있는 인터넷 쇼핑몰에서의 패션제품 구매에 대한 소비자 이해를 제시하는 선 행변수들을 밝히고자 한다. 선행변수로서 심리적 변 수와 패션관련 심리적 변수를 선정하고, 종속변수로 패션제품 구매빈도를 선정하여 경로를 설정하였다. 심리적 변수는 지루함과 공적 자의식을, 패션관련 심리적 변수는 스타일 지향성을 선정하였다. 구체적 으로 심리적 변수인 지루함, 공적 자의식이 인터넷 패션제품 구매빈도에 직접적인 영향을 줄 뿐 아니 라, 패션관련 심리적 변수인 스타일 지향성을 통해 서 인터넷 패션제품 구매빈도에 영향을 준다는 경로를 설정하고 분석하였다. 설정된 연구모형은〈Fig. 1〉과 같으며, 가설은 다음과 같다.

가설 1-1: 지루함 성향이 높을수록 인터넷 패션제 품 구매빈도는 높을 것이다.

가설 1-2: 지루함 성향이 높을수록 스타일 지향성 이 낮을 것이다. 


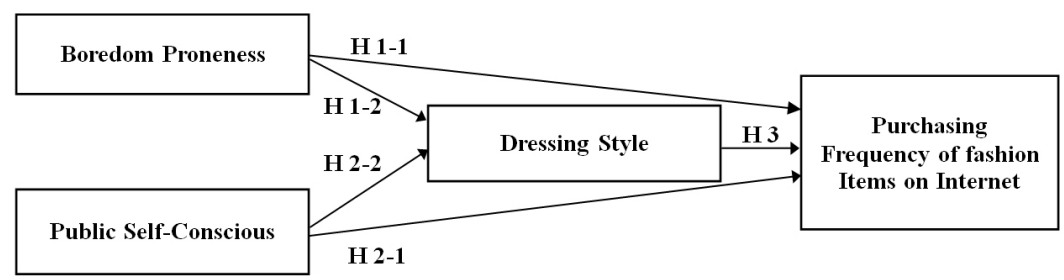

〈Fig. 1〉 Hypothesized model

가설 2-1: 공적 자의식이 높을수록 인터넷 패션제 품 구매빈도는 높을 것이다.

가설 2-2: 공적 자의식이 높을수록 스타일 지향성 이 높을 것이다.

가설 3: 스타일 지향성이 높을수록 인터넷 패션 제품 구매빈도는 높을 것이다.

\section{Measurement and analysis}

본 연구를 위하여 지루함 성향, 공적 자의식, 스 타일 지향성, 인터넷 패션제품 구매빈도와 함께 인 구통계적 변수에 대한 문항을 포함한 설문지를 이 용하였다. 지루함 성향을 측정하기 위해서 Farmer and Sundberg(1986)의 28문항을 사용하였다. 그런데 척 도는 진위형(true-false)으로 측정하는 것으로 개발, 제시되었으나, Workman and Studak(2005)을 포함한 지루함 성향에 대한 대부분의 연구들이 5 점 리커트 (Likert)형으로 측정하여 높은 내적 일관성을 보였 다. 따라서 본 연구는 리커트 형으로 측정하였다. 또 한 공적 자의식을 측정하기 위해서 Fengstein et al. (1975)의 7문항을 사용하였다. Fengstein et al.(1975) 의 척도는 다소 오래 되었음에도 불구하고, 해외에 서 새로운 척도의 개발, 제시가 없이 모든 연구들이 사용하고 있으므로 문제가 없다고 본다. 또한 국내 에서도 최근의 상담학 연구(Lee \& Hong, 2013)와 의류학 연구들(Hong, 2010; Jeon \& Yoo, 2011; Ryoo \& Yoo, 2007; Lee, 2010a, 2010b)이 그들의 척 도를 사용하고 있다. 스타일지향성을 측정하기 위하 여 Wan et al.(2001)의 4문항을 사용하였다.

지루함 성향, 공적 자의식, 스타일 지향성의 경 우, 1 점은 ‘전혀 그렇지 않다'에서 5점은 '매우 그렇 다’로서 5점 리커트형으로 측정되었다. 즉, 점수가 높을수록 지루함 성향, 공적 자의식, 스타일 지향성
이 높은 것을 의미한다. 인터넷 구매는 인터넷 쇼핑 몰에서의 패션제품에 대한 구매빈도로 측정하였는 데, 본 연구가 행하여진 시점이 12 월이어서 한 해 동안의 구매빈도를 숫자로 자유기술하도록 하였다. 소비자들이 인터넷 쇼핑몰에서 의류와 함께 다양한 패션제품을 구매하기 때문에, 구매빈도에 대한 질문 에 있어서 패션제품을 의류 외에 가방, 액세서리 포 함하는 포괄적인 의미라는 것을 명시하였다. 그리고 응답자의 인터넷 구매에 대한 추가적인 정보를 얻 기 위하여 인터넷 쇼핑몰에서 가장 최근에 구매한 패션제품의 종류와 가격을 각각 자유기술식으로 제 시하도록 하였다.

2 개 이상의 문항으로 구성된 지루함 성향, 공적 자의식, 스타일 지향성에 대하여 탐색적 요인분석을 실시하였다. 탐색적 요인분석의 통계처리는 SPSS 18.0 통계 패키지를 이용하여 주성분분석과 베리맥 스 회전방법을 사용하였다. 가설화된 경로를 위해 구조방정식 모형분석을 이용하였는데, 이를 위하여 AMOS 18.0 프로그램을 사용하였다. 모수 추정방법 은 최대우도비 추정방법을 이용하였다. 그 외에 SPSS 18.0 을 이용하여 신뢰도 분석과 기술통계를 행하였다.

\section{Data collection}

본 연구의 자료 수집을 위하여 서울과 주변 신도 시에 거주하는 20 대 대학생을 편의 추출하여 설문 조사한 결과, 회수된 설문지 중 응답이 불성실한 설 문지를 제외한 286 부를 분석에 사용하였다. 통계처 리에 사용된 응답자의 평균연령은 만 22.86 세 $(S D=$ 2.30 )였으며, 남성 184 명(64.3\%) 여성은 99명(34.6\%) 이었다. 응답자의 인터넷 쇼핑몰에서 패션제품에 대 한 구매빈도의 평균은 $8.90(S D=9.20)$ 으로 나타났다. 또한 인터넷 쇼핑몰에서의 가장 최근에 구매한 패 
션제품의 종류를 기재한 응답자 $(N=214)$ 중에서 의 류가 152 명 $(71 \%)$, 가방이 15 명(7\%), 액세서리가 20 명(9.3\%), 구두가 25 명 $(11.7 \%)$, 기타가 2명 $(.9 \%)$ 으로 나타나 응답자의 대부분이 의류를 구매한 것으로 나 타났다. 구매한 패션제품의 평균가격은 $118,232.68$ 원 $(S D=188,755.348)$ 이었다.

\section{Results and Discussion}

\section{Factor analysis}

지루함 성향, 공적 자의식, 스타일 지향성 변수들 에 대해 탐색적 요인분석을 실시한 결과, 스타일 지 향성은 단일요인으로, 지루함 성향과 공적 자의식은 다차원으로 나타났다. 설명력은 $64.45 \%$ 로 나타났으 며, Cronbach's a는 .81로 나타났다. 스타일 지향성 이 1 요인으로 나타난 결과는 국내 대학생을 대상으
로 연구한 Park(2013)과 같다. 지루함 성향과 공적 자 의식에 대한 요인분석과 신뢰도분석의 결과는〈Table 1 , 〈Table 2〉와 같다.

지루함 성향의 요인분석 결과, 한 개 이상의 요인 에 교차적재된 문항과 요인적재량이 .50 이하를 보 인 문항인 13 개 문항을 제외한 후 5 개 요인을 추출 하였다(Table 1). 설명력이 큰 요인부터 적재된 문항 들을 고려하여 요인명을 무력감(helplessness), 정서 적 반응, 내적 자극 결여, 외적 자극 결여, 시간 지각 으로 명명하였다. 본 연구에서의 내적 자극 결여 요 인과 외적 자극 결여 요인은 지루함 성향에 대한 선 행연구에서의 '내적 자극'과 '외적 자극' 요인들과 같은 문항들로 구성되어 있으나, 요인에 대한 자세 한 설명을 위해 요인명에 결여를 포함하였다. 각각 의 설명력이 $18.59 \%, 13.16 \%, 11.65 \%, 10.14 \%, 9.27 \%$ 로서 총 설명력은 $62.80 \%$ 로 나타났다. 또한 Cronbach's

〈Table 1〉 Factor analysis of boredom proneness

\begin{tabular}{|c|c|c|c|c|c|}
\hline $\begin{array}{l}\text { Factor } \\
(N=286)\end{array}$ & Item & $\begin{array}{c}\text { Factor } \\
\text { loading }\end{array}$ & $\begin{array}{l}\text { Eigen } \\
\text { value }\end{array}$ & $\begin{array}{c}\text { Variance } \\
\%\end{array}$ & $\begin{array}{c}\text { Cronbach's } \\
\text { a }\end{array}$ \\
\hline \multirow{5}{*}{ Helplessness } & I often find myself with nothing to do-time on my hands. & .87 & \multirow{5}{*}{2.79} & \multirow{5}{*}{18.59} & \multirow{5}{*}{.79} \\
\hline & I often find myself at "loose end," not knowing what to do. & .81 & & & \\
\hline & Much of the time I just sit around doing nothing. & .66 & & & \\
\hline & Time always seems to be passing slowly. & .62 & & & \\
\hline & $\begin{array}{l}\text { I am often trapped in situations where I have to do meaningless } \\
\text { things. }\end{array}$ & .55 & & & \\
\hline \multirow{3}{*}{$\begin{array}{l}\text { Affective } \\
\text { response }\end{array}$} & $\begin{array}{l}\text { In any situation I can usually find something to do or see to } \\
\text { keep me interested. }\end{array}$ & .77 & \multirow{3}{*}{1.97} & \multirow{3}{*}{13.16} & \multirow{3}{*}{.72} \\
\hline & I get a kick out of most things I do." & .77 & & & \\
\hline & I find it easy to entertain myself. & .71 & & & \\
\hline \multirow{3}{*}{$\begin{array}{l}\text { Lack of internal } \\
\text { stimulation }\end{array}$} & $\begin{array}{l}\text { Many people would say that I am a creative or imaginative } \\
\text { person. }\end{array}$ & .74 & \multirow{3}{*}{1.75} & \multirow{3}{*}{11.65} & \multirow{3}{*}{.61} \\
\hline & I have so many interests, I don't have time to do everything. ${ }^{*}$ & .73 & & & \\
\hline & I often wake up with a new idea. & .73 & & & \\
\hline \multirow{2}{*}{$\begin{array}{l}\text { Lack of external } \\
\text { stimulation }\end{array}$} & Many things I have to do are repetitive and monotonous. & .77 & \multirow[b]{2}{*}{1.52} & \multirow[b]{2}{*}{10.14} & \multirow[b]{2}{*}{.53} \\
\hline & $\begin{array}{l}\text { It would be very hard for me to find a job that is exciting } \\
\text { enough. }\end{array}$ & .68 & & & \\
\hline \multirow{2}{*}{$\begin{array}{l}\text { Perception of } \\
\text { time }\end{array}$} & I am good at waiting patiently. & .80 & \multirow[b]{2}{*}{1.39} & \multirow[b]{2}{*}{9.27} & \multirow[b]{2}{*}{.49} \\
\hline & $\begin{array}{l}\text { In situations where I have to wait, such as a line or queue, I get } \\
\text { very restless. }\end{array}$ & .77 & & & \\
\hline
\end{tabular}

Note. ${ }^{*}$ Means reverse scored item. 
$\mathrm{a}$ 는 무력감 .79 , 정서적 반응 . 72 로 나타나서 내적 타당성은 문제가 없다고 본다. 그러나 내적 자극 결 여는 .61 , 외적 자극 결여는 .53 , 시간 지각은 .49 로 다소 낮게 나타났다. 신뢰도 수준에 대하여 $\mathrm{Bae}(2011)$ 는 일반적으로 수용 가능한 신뢰도 수준은 .70 이 상이지만, .70 이하라도 탐색적 성격을 갖고 있다 면 수용 가능하다고 하였으므로 세 요인들을 수용 하였다.

Farmer and Sundberg(1986)의 척도를 사용하여 5 요인을 추출한 Vodanovich and Kass(1990)와 같이 본 연구에서도 5요인을 추출하였으나, Vodanovich and $\operatorname{Kass}(1990)$ 의 다르게 억제 요인은 나타나지 않 았으며, 억제 요인 대신 무력감 요인이 나타났다. 그 런데 국내 소비자를 대상으로 지루함 성향을 분석 한 연구도 미흡할 뿐 아니라, Farmer and Sundberg (1986)의 척도를 이용하여 지루함 성향을 분석한 연 구도 없으므로 본 연구결과를 국내 연구 결과와 비교 하는 것이 불가능하다. 따라서 Farmer and Sundberg (1986)의 척도를 사용하여 탐색적 요인분석을 제시 한 유일한 국내 연구라는데 의의가 있으므로, 본 연 구의 요인분석 결과를 해외 연구 결과와 다음과 같 이 깊이 있게 비교하고자 한다.

Farmer and Sundberg(1986)의 척도는 지루함을 경 험하는 성향을 측정하기 위해 단일 차원의 점수로 개발된 척도이므로, 해외에서 그들의 척도를 이용하 여 측정한 지루함 성향과 다른 변수들과의 관계를 밝히거나 영향을 밝힌 연구들의 대부분이 탐색적 요인분석 없이 단일차원으로 보았다. 그러나 지루함 성향에 대한 차원의 분류는 다양한 지루함 성향에 대한 상세한 평가가 가능하게 하므로(Vodanovich et al., 2005), 지루함 성향에 대한 요인분석을 실시한 연구들이 진행되었는데, 다수의 연구들이 5요인을 추출하였으며, 그 외는 $8,2,3$ 요인을 추출하였다.

미국 대학생을 대상으로 Vodanovich and Kass (1990)는 탐색적 요인분석을 통해 요인부하량 .40 이상의 문항들을 포함하여 5 개 요인(외적 자극, 내 적 자극, 정서적 반응, 시간 지각, 억제)을 추출하였 다. 총 $43 \%$ 의 설명력과 신뢰성 계수는 .59부터 .73 까지로 나타났다. Vodanovich and Kass(1990)에 기 반하여 미국 대학생을 대상으로 한 다음의 연구들 은 5요인을 지정하여 실시하였다. Vodanovich et al.
(2011)은 5요인으로 지정하여 요인 별 미국과 독일 의 대학생의 차이와 성별 차이를 밝혔으며, Vodanovich and Watt(1999)도 5요인으로 지정하여 요인 별로 아 일랜드와 미국 대학생의 개인의 시간구조 지각의 차이를 밝혔다. Seib and Vodanovich(1998)도 미국 대학생을 대상으로 5 요인으로 지정하여 요인 별로 자의식과 열중(absorption)과의 관계를 밝혔다. Watt and Vodanovich(1999)도 5요인으로 지정하여 미국 대학생의 사회심리학적 발전과의 관계를 밝혔다. 패 션과 관련하여 미국 대학생을 대상으로 Studak and Workman(2004)도 5요인으로 지정하여 패션에 대한 혁신자, 의견선도자, 혁신적 커뮤니케이터, 추종자 의 집단에 따른 지루함 성향에 대한 차이와 성별에 따른 지루함 성향의 차이를 밝혔다. 미국 여대생을 대상으로 Workman and Studak(2005)도 5요인으로 지정하여 요인 별로 내재적 즐거움(intrinsic enjoyment) 과 내외통제(locus of control)와의 관계를 분석하였다. 이상의 5 요인을 추출한 연구 외에 미국 흑인 대 학생을 대상으로 Vodanovich, Watt, and Piotrowski (1997)는 탐색적 요인분석 시 요인부하량 40 이상 의 문항들을 포함하여 8 개 요인을 추출하였으며, $56.4 \%$ 의 총설명력을 나타냈다. 8 요인은 시간 지각, 내적 자극; 창의성, 외부자극: 단조로움, 억제, 감정, 참을성, 내적 자극: 주의 유지, 외적 자극: 도전이었 다. 또한 Rupp and Vodanovich(1997)는 미국 대학생 을 대상으로 지루함 성향이 높을수록 분노(anger)와 공격성(aggression)이 높음을 밝혔다. 그들은 캐나다 대학생을 대상으로 연구하여 두 요인을 추출한 Ahmed (1990)의 환경에 대한 관심부족을 나타내는 무관심 (apathy)과 개인의 집중과 주의를 기울이는 능력을 나타내는 부주의(inattention)가 개념적으로 Vodanovich and $\operatorname{Kass}(1990)$ 의 내적 자극과 외적 자극 요인들과 같다고 보았다. 그래서 내적 자극과 외적 자극 요인 두 요인으로 보고 분석하였다. 프랑스 성인을 대상 으로 지루함 성향과 내성적임과의 관련성을 연구한 Gana, Deletang, and Metais(2000)은 지루함 성향에 대한 탐색적 요인분석 결과, 외부자극, 내부자극, 성 급함(impatience)의 3요인을 추출하였으나, 두 문항 이 적재된 성급함 요인을 제외하였다.

이상의 선행연구에서 추출된 요인 수의 차이는 연 구대상이 다르기 때문인 것으로 보인다. 또는 Farmer 
and Sundberg(1986)의 척도를 사용하였으나, 다른 방법으로 측정하였기 때문일 수도 있다. Gana et al. (2000)과 Ahmed(1990)는 진위형으로 측정하였으나, 다른 연구들은 리커트형으로 측정하였다. 이에 대하 여 Vodanovich et al.(2005)은 선행연구들이 같은 척 도를 사용하였으나, 응답의 측정에 대한 차이가 있 으므로 요인분석 결과에 대한 비교가 부족하다고 지적하고, 미국 성인들을 대상으로 각 6 문항으로 구 성된 내적 자극과 외적 자극의 두 요인으로 구성된 축약형(short form) 척도를 제시하였다. 그러나 축약 형 척도의 적합성에 대한 후속 연구들은 진행되고 있지 않았다. 최근에 적합한 요인 수를 집중적으로 연구한 Melton and Schulenberg(2009)는 대학생을 대상으로 요인분석에 대한 선행연구들의 결과대로, $1,2,4,5$ 요인으로 확인적 요인분석을 실시한 결과, 모두 적합성이 낮다는 것을 밝혔다. 그리고 탐색적 요인분석을 다시 실시한 결과, 2 요인을 추출하였다. 그리고 선행연구들과의 불일치에 대하여 지루함 성 향 척도는 같은 요인 구조를 갖지 않는 것으로 보인 다고 주장하였으며, 선행연구들의 요인분석의 다양 한 결과는 연구대상에 따른 차이로 보인다고 분석 하였다.

본 연구의 국내 대학생을 대상으로 한 지루함 성 향의 요인분석 결과를 미국 대학생을 대상으로 5 요 인을 추출한 Vodanovich and Kass(1990)와 비교하 면 다음과 같다. 본 연구에서는 지루함 성향에 대한 설명력은 무력감, 정서적 반응, 내적 자극 결여, 외적 자극 결여, 시간 지각의 순서로 나타났다. Vodanovich and $\operatorname{Kass}(1990)$ 는 외적 자극, 내적 자극, 정서적 반 응, 시간 지각, 억제의 순서로 나타났다. 즉, 국내 대 학생은 자신의 무력감에 의해 지루함을 느끼는데
비해, 미국 대학생은 외적 자극 결여에 의해 지루함 을 느낀다는 것을 의미한다. 이러한 결과는 대학생 을 둘러싼 국내 환경이 미국보다는 외적 자극이 많 다는 것을 의미할 뿐 아니라, 그럼에도 불구하고 지 루함을 느끼는 국내 대학생의 지루함 성향은 자신 의 무력감으로 인한 것이 크다는 것을 의미한다.

공적 자의식은 교차 적재된 2 개 문항을 제외한 후, 2 개의 요인을 추출하였다. 첫째 요인은 다른 사 람들에게 보여지는 외모에 주의를 기울이는 문항으 로 구성되어 있고, 둘째 요인은 행동 스타일에 대해 주의를 기울이는 문항으로 구성되어 있다. 두 요인 에 적재된 문항들은 Fengstein et al.(1975)의 척도를 사용하여 Mittal and Balasubramanian(1987)과 Nystedt and Ljungberg(2002)이 추출한 두 요인인 외모 의식 과 스타일 의식에 적재된 문항들과 외모 의식의 한 문항을 제외하고는 모두 동일하게 나타났다. 따라 서 그들과 같이 첫째 요인은 '외모 의식'으로 명명 하였으며, 둘째 요인은 '스타일 의식'으로 명명하였 다. Cronbach's a는 외모 의식 .74로, 스타일 의식 .75 로 나타나서 측정도구의 내적 타당성은 문제가 없다고 본다. 총 설명력은 $72.90 \%$ 로 나타났다.

본 연구와 같은 척도를 사용하여 국내 소비자를 대상으로 한 다음의 연구들이 탐색적 요인분석을 통해 공적 자의식의 차원을 밝히지 않았으므로 두 차원으로 밝혀진 본 연구 결과가 시사하는 바가 크 다. 성인여성을 대상으로 연구한 Jeon and $\mathrm{Yoo}(2011)$, 여대생을 대상으로 한 Lee(2010b)와 대학생을 대상 으로 한 Lee(2010a)는 탐색적 요인분석을 행하지 않 았으며, 대학생을 대상으로 한 Lee and Hong(2013) 은 탐색적 요인분석에서 1 개의 요인으로 지정하여 실시하였다. 또한 여대생을 대상으로 한 $\operatorname{Hong}(2010)$

〈Table 2〉 Factor analysis of public self-consciousness

\begin{tabular}{|c|c|c|c|c|c|}
\hline $\begin{array}{l}\text { Factor } \\
(N=286)\end{array}$ & Item & $\begin{array}{l}\text { Factor } \\
\text { loading }\end{array}$ & $\begin{array}{l}\text { Eigen } \\
\text { value }\end{array}$ & $\begin{array}{l}\text { Variance } \\
\%\end{array}$ & $\begin{array}{c}\text { Cronbach's } \\
\text { a }\end{array}$ \\
\hline \multirow{3}{*}{$\begin{array}{l}\text { Appearance- } \\
\text { consciousness }\end{array}$} & I'm usually aware of my appearance. & .87 & \multirow{3}{*}{1.97} & \multirow{3}{*}{39.42} & \multirow{3}{*}{.74} \\
\hline & $\begin{array}{l}\text { One of the last things I do before I leave the house is look } \\
\text { in the mirror. }\end{array}$ & .83 & & & \\
\hline & I'm concerned about what other people think of me. & .70 & & & \\
\hline \multirow{2}{*}{ Style-consciousness } & I'm concerned about my style of doing things. & .88 & \multirow{2}{*}{1.67} & \multirow{2}{*}{33.48} & \multirow{2}{*}{.75} \\
\hline & I'm very concerned about the way I present myself. & .87 & & & \\
\hline
\end{tabular}


은 Fengstein et al.(1975)의 7문항 중 4개의 문항만을 사용하여 1 개의 요인을 추출하였다. 또한 노년여성 을 대상으로 한 Ryoo and Yoo(2007)는 탐색적 요인 분석을 행하지 않고 공적 자의식, 사적 자의식, 사회 적 불안의 3 개 요인으로 지정하여 각 요인에 따른 외모관리 행동을 분석하였다. 그러나 해외에서 Mittal and Balasubramanian(1987)과 Nystedt and Ljungberg (2002)은 Fengstein et al.(1975)의 척도를 사용하여 공 적 자의식이 한 개의 요인일 때보다 외모 의식과 스타 일 의식의 두 요인인 경우 적합도가 더 높음을 밝히며, 두 요인임을 지지하였다. Mittal and Balasubramanian (1987)은 미국 대학생을 대상으로 내적 외적 일관성 계수(internal and external consistency coefficients)분 석을 통해 공적 자의식이 한 개의 요인보다 스타일 의식과 외모 의식의 두 요인이 적합함을 밝혔다. 또 한 Nystedt and Ljungberg(2002)은 스웨 덴 고등학생 을 대상으로 하여 탐색적 요인분석을 통해 외모 의 식과 스타일 의식의 두 요인을 추출하였다. 이상의 두 연구에서의 외모 의식과 스타일 의식에 적재된 문항들과 본 연구에서 적재된 문항들이 1 문항을 제 외하고는 모두 동일하게 나타났다. 특히 Nystedt and Ljungberg(2002)에서 설명력의 크기가 외모 의식, 스타일 의식의 순서로 나타난 것은 본 연구의 결과 와 같다. 따라서 본 연구결과에 의해 국내 소비자를 대상으로 공적 자의식을 1 개의 요인으로 분석한 선 행연구와 다르게 두 요인으로 보는 것을 적합하다
고 본다. 또한 외모 의식의 설명력이 높게 나타난 결 과는 국내 소비자의 공적 자의식에 있어서의 외모 의 중요성을 나타낸다.

\section{Hypothesized relationship test}

인터넷 패션제품 구매빈도에 유의한 영향을 주는 선행변수를 밝히기 위하여 구조방정식 모형분석을 하였다. 구조방정식 모형에서는 대부분 외생변수들 은 서로 상관되어 내생잠재변수에게 공유된 영향력 을 주는 것으로 설정되기 때문에(Bae, 2011), 외생변 수인 심리적 변수들간의 비인과적 상관관계를 설정 하여 분석하였다. 그리고 심리적 변수들간에 상관관 계를 보이는 것이 일반적이므로, 비인과적 상관관계 를 설정하는 것이 옳다고 본다. 산출된 10 이상의 수정지수 중에서 $\mathrm{Bae}(2011)$ 가 제시한대로 4개의 같 은 요인 내 측정오차상관만을 허용하였다. 공분산을 설정한 후 선행변수에서 구매빈도에 이르는 경로가 유의하지 않은 것을 삭제한 후, 모형분석을 다시 실 시하였다. 최종 수정된 모형의 적합도는〈Table 3〉 과 같으며, 표준화 경로계수(regression weights)와 설명력을 제시한 것은〈Fig. 2〉와 같다. 〈Fig. 2〉에서 타원형은 잠재변수를 나타내며, 직각형은 측정변수 를 나타낸다. 또한 화살표의 실선은 유의한 경로를 내며, 점선은 유의하지 않은 경로를 나타낸다.

최종 모형에 대한 적합성 결과를 보면(Table 4), $X^{2}$ 값이 .05 이하로 통계적으로 유의하게 나타났으며,

〈Table 3〉 Fit Statistics for model in Fig. 2.

\begin{tabular}{c|c|c|c|c|c|c|c|c|c}
\hline Measures & $\mathrm{X}^{2}$ & $p$ & RMR & GFI & AGFI & TLI & CFI & RMSEA & PCLOSE \\
\hline$N=286$ & 438.20 & .00 & .19 & .89 & .86 & .90 & .91 & .05 & .64 \\
\hline
\end{tabular}

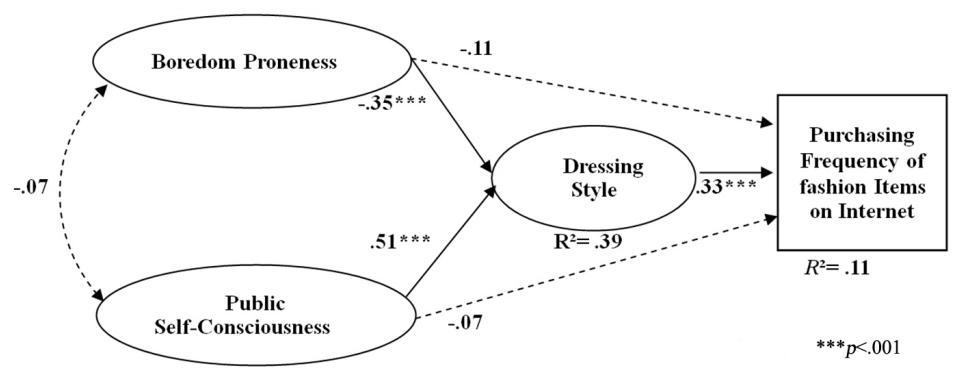

〈Fig. 2〉 Path coefficient in the hypothesized model 
$\mathrm{RMR}$ 은 .05 이상으로 나타났다. 그러나 다른 적합성 지수(GFI, AGFI, TLI, CFI)가 모두 최저 적합성 기 준인 .90 에 가깝게 나타났다. AGFI가 .86으로 다소 낮게 나타났으나, 적합성 지수로 많이 사용하는 CFI 가 .91로서 적합성지수 중 가장 높게 나타났다. 또한 RMSEA가 .10보다 작고, PCLOSE가 .05보다 크게 나타났다. 이상의 결과는 가설화된 모형에 대하여 수정지수에 의한 4 개의 공분산만을 허용한 것에 비 하면 비교적 높은 적합성 지수를 보인 것으로 볼 수 있다. 따라서 적합성에는 문제가 없다고 본다. 그리 고 제시된 적합성지수 외에 절대 적합지수인 $Q$ 값을 추가적으로 산출해 보았다. 수정전의 가설화된 연구 모형의 $Q$ 값은 1.895 이었으나, 수정된 최종모형에 대한 $Q$ 값은 1.660 으로서 1 에 더 가까운 수치를 보 여주었다. $Q$ 값이 1 에 가까울수록 제시된 모형과 자 료의 높은 적합도를 보여주므로(Kim, 2001), 최종모 형을 채택하여 인터넷 구매빈도에 유의한 영향을 주는 선행변수를 살펴보았다.

스타일 지향성과 구매빈도의 다중상관자승(squared multiple correlation: $R^{2}$ )이 .39와 .11로 나타났다. 따 라서 스타일 지향성의 $39 \%$ 가 유의한 선행변수인 지 루함 성향과 공적 자의식에 의해 설명되고, 구매빈 도의 $11 \%$ 는 유의한 선행변수인 지루함 성향, 공적 자의식, 스타일 지향성에 의해 설명되고 있음을 알 수 있다. 스타일 지향성에 대하여 $40 \%$ 가까운 높은 분산은 연구모형에 포함된 심리적 변수들에 의해 잘 설명되고 있음을 나타내지만, 구매빈도의 $11 \%$ 의 비교적 낮은 분산은 본 모형에 포함된 심리적 변수 와 스타일 지향성 외에도 다른 변수들에 의해 설명 되고 있음을 나타낸다.

유의한 경로계수를 보면, 〈Fig. 2〉와 같이 지루함 성향(경로계수 $=-.35, p<.001$ )과 공적 자의식(경로 계수 $=.51, p<.001)$ 에서 스타일 지향성에 이르는 경 로가 유의하게 나타났다. 또한 스타일 지향성(경로 계수=.33, $p<.001)$ 에서 구매빈도에 이르는 경로도 유의하게 나타났다. 유의한 경로계수에 의해 가설 $1-2$, 가설 $2-2$, 가설 3 은 채택되었다. 소비자의 심리 적 변수들인 지루함 성향과 공적 자의식이 스타일 지향성을 통해 패션제품 구매빈도에 영향을 미치므 로 스타일 지향성 변수가 중요하다는 것을 나타낸 다. 따라서 심리적 변수가 구매빈도에 직접적인 영
향을 주는 것을 밝히기 보다는 매개변수로서 스타 일 지향성과 같은 패션관련 심리적 변수를 함께 밝 히는 것이 인터넷에서 패션제품 구매빈도에 대한 소비자 이해를 제시한다는 것을 알 수 있다. 지루함 이 구매빈도에 정적 영향을 미칠 것으로 본 가설 1-1이 기각된 결과에 의해 지루함 성향이 충동성에 정 적인 영향을 준다는 것을 밝힌 Watt and Vodanovich (1992)의 연구결과를 인터넷에서의 패션제품 구매 로 확대 적용할 수 없다는 것을 알 수 있다. 또한 공 적 자의식이 구매빈도에 정적 영향을 미칠 것으로 본 가설 2-1이 기각된 결과에 의해 오프라인상에서 의 패션제품 구매에 정적 영향을 준다고 밝혀진 심 리적 변수인 공적 자의식이 인터넷 구매에서 영향 을 주지 않는다는 알 수 있다. 따라서 오프라인과 온 라인에서의 구매행동에 영향을 주는 심리적 변수의 차이에 대한 연구가 필요하다.

유의한 경로계수의 방향을 보면, 지루함 성향이 스타일 지향성에 미치는 영향이 부적으로 나타났 다. 또한 공적 자의식은 스타일 지향성에 정적 영 향을 미쳤으며, 스타일 지향성도 구매빈도에 정적 영향을 미쳤다. 이상의 결과에 의해 지루함 성향이 클수록 스타일 지향성은 낮아져서 구매빈도도 낮 아지는데 비해, 공적 자의식을 클수록 스타일 지향 성이 높아지고, 구매빈도가 높아진다는 것을 알 수 있다.

심리적 변수들에서 스타일 지향성에 이르는 경로 의 크기를 보면, 공적 자의식이 .51로 가장 컸으며, 지루함 성향은 -.35 로 나타났다. 이상의 결과는 스 타일 지향성을 결정하는데 있어서 지루함 성향보다 는 공적 자의식이 더 중요하다는 것을 의미한다. 따 라서 스타일 지향성에 유의한 영향을 주는 변수들 의 상대적 영향력에 대한 이해는 연구자에게는 소 비자 이해 시 중심이 되어야 하는 심리적 변수를 제 시하며, 마케터에게는 전략 수립 시 총력을 다해 만 족시켜야 할 중요 심리적 변수에 대한 이해를 제시 한다.

상관관계를 보면, 지루함 성향과 공적 자의식은 유의하지 않았다. 이러한 결과는 미국 대학생을 대상 으로 하여 지루함 성향이 공적 자의식과 상관관계가 나타나지 않았음을 밝힌 Von Gemmingen, Sullivan, and Pomerantz(2003)와 일치한다. 


\section{Conclusion}

급성장하고 있는 인터넷 쇼핑몰에서의 패션제품 구매에 대한 소비자 이해를 제시하고자 하는 연구 가 다양하게 진행되었다. 대부분의 연구들이 인터넷 쇼핑몰의 구매특성과 만족도에 영향을 주는 쇼핑몰 의 자극요인 등을 밝히고, 쇼핑을 이끄는 소비자의 쇼핑성향과 쇼핑가치 또는 심리적 특성 중에서도 충동구매와 혁신성향을 밝히고 있다. 본 연구는 지 루함 성향과 공적 자의식이라는 심리적 변수와 스 타일 지향성이라는 패션관련 심리적 변수로 인터넷 에서 패션 제품의 구매에 대한 새로운 이해를 제시 하고자 하였다. 이를 위하여 지루함과 공적 자의식 이 인터넷 패션제품 구매빈도에 영향을 줄 뿐 아니 라, 패션관련 심리적 변수인 스타일 지향성을 통해 서 인터넷 패션제품 구매빈도에 영향을 준다는 연 구모형을 제시하고, 이를 구조방정식 모형으로 검증 하였다.

본 연구의 의의는 다음과 같다. 첫째, 패션 인터 넷 쇼핑몰의 성장은 쇼핑몰의 전략 외에도 젊은 세 대들의 심리적 특성인 지루함 성향과 과시적인 패 션제품의 구매와 관련이 높은 공적 자의식에 의한 것이라고 보고, 이를 밝히는데 있다. 특히 의류학을 포함한 모든 학문에서 국내 소비자의 지루함을 밝히 는 연구가 미흡할 뿐 아니라, Farmer and Sundberg (1986)의 척도를 이용하여 지루함 성향을 요인분석 한 연구도 없으므로 본 연구의 지루함 성향에 대한 요인분석 결과가 시사하는 바는 크다. 따라서 지루 함 성향에 대한 요인분석 결과를 심도 있는 논의를 제시했다는 것에 의의가 크다. 둘째, 소비자의 구 매빈도에 직접적인 영향을 주는 심리적 변수만 밝 히는 것보다 매개변수로서 스타일 지향성과 같은 패션관련 심리적 변수를 함께 밝히는 것이 인터넷 에서 패션제품 구매에 대한 소비자 이해를 구체적 으로 제시한다는 것을 밝힌 것에 의의가 있다.

연구결과에 의한 결론 및 제언은 다음과 같다.

첫째, 지루함 성향에 대한 요인분석에서 무력감, 정서적 반응, 내적 자극 결여, 외적 자극 결여, 시간 지각의 순서로 나타난 결과는 국내 소비자의 지루 함 성향에 대한 이해를 제시한다. 국내 소비자의 지 루함 성향은 자신의 무력감에 의한 것이 크다는 것
을 의미한다. 또한 마케터는 지루함 성향을 결정하 는 요인들 중 시장전략에 의해 통제 가능한 요인이 외적 자극 결여 요인인데, 이 요인이 낮게 나타난 것 에 주목할 필요가 있다. 마케터는 마케팅 전략에 의 해 통제 가능하거나, 조절 가능한 외적 자극 결여 요 인의 설명력이 낮기 때문에, 소비자의 지루함을 통 제할 수 없다는 것을 이해하여야 한다. 즉, 지루함을 통제, 조절하기 보다는 소비자의 지루함 성향 자체 를 이해하고, 변화 추이를 관찰해야 하며, 지루함 성 향에 영향을 주는 변수들을 밝히는데 주력해야 할 것이다.

둘째, 공적 자의식에 대한 요인분석에서 외모 의 식, 스타일 의식 순서로 나타났다. 국내 소비자는 외 모에 의해 공적 자의식을 많이 느낀다는 것을 의미 하는데, 이는 패션산업에 시사하는 바가 크다. 자신 의 행동 스타일보다 외모에 의해 공적 자의식을 느 낀다는 것은 소비자에게 있어서 패션의 중요성이 크다는 것을 의미하므로, 패션산업의 미래는 밝다고 할 수 있다. 마케팅 전략에 있어서 이러한 결과를 효 과적으로 이용하기 위해서는 촉진전략 수립 시에 공적 자의식에 있어서의 외모관리 중요성을 메시지 로 전달한다면 패션시장은 계속적으로 성장할 수 있을 것이다. 또한 자사 브랜드에 의한 성공적인 외 모관리가 가능하다는 메시지를 전달하면 브랜드 마 케팅에 효과적일 것이다. 또한 제품전략에 있어서도 성공적인 외모관리가 가능한 경쟁력 있는 패션제품 들을 다양하게 제시하여야 할 것이다.

셋째, 유의적인 경로계수를 보면, 지루함 성향과 공적 자의식이 스타일 지향성을 통해 구매빈도에 영향을 주는 것으로 나타났다. 따라서 마케터는 인 터넷 패션제품 구매빈도에 직접적인 영향을 주는 소비자의 스타일 지향성의 중요성을 인지하고, 이 에 소구하는 전략을 구사하여야 한다. 우선적으로 지루함 성향이 구매빈도에 영향을 주지 않는 것으 로 나타난 결과는 소비자가 지루할 때 손쉽게 인터 넷을 통해 패션제품을 구매하지 않는다는 것을 의 미한다. 지루함이 패션제품에 대한 인터넷 쇼핑 구 매빈도에 영향을 주지 않는 것으로 나타난 이유에 대하여 다음의 두 가지로 유추할 수 있다. 지루함을 느끼는 소비자는 패션제품 자체에 대한 구매욕구를 느끼지 않을 수도 있으며, 인터넷 쇼핑과 같은 외적 
자극을 통해 지루함을 해소하지 않을 수도 있다는 것이다. 따라서 패션 인터넷 쇼핑몰의 마케터는 전 략 수립 시 소비자의 지루함을 해소하기 위한 수단 으로서 구매를 유도하기 보다는 제품의 필요를 자 극하거나, 패션제품에 대한 지식을 전달하면서 구 매의 필요성을 인식시키는 것이 효과적일 것이다. 또한 스타일 지향성이 구매빈도에 미치는 유의적인 영향에 대한 이해를 바탕으로 인터넷 쇼핑몰 마케 터는 제품전략에서 소비자의 패션 스타일 지향성을 만족시키기 위해 다양한 스타일 지향적인 제품을 제시하여야 할 것이다. 촉진전략에 있어서도 쇼핑 몰이 스타일 지향적인 다양한 패션제품을 구비하 고 있다는 것을 제시하고 전달하여야 할 것이다. 또한 소비자의 스타일 지향성이 높을수록 구매빈 도가 높아지므로, 스타일 지향성에 유의적인 영향 을 주는 변수로 나타난 소비자의 지루함 성향과 공 적 자의식에 마케팅 노력을 집중하여야 한다. 특히 공적 자의식이 지루함 성향에 비해 스타일 지향성 에 미치는 상대적 영향력이 크게 나타난 것에 유의 하여서 자사브랜드에 의한 성공적인 자기관리가 가 능하다는 메시지의 전달과 함께 성공적인 외모와 스타일관리가 가능한 제품들을 제시하는데 주력해 야 할 것이다.

본 연구의 한계점과 이에 따른 후속연구에 대한 제언은 다음과 같다.

첫째, 최종모형에서 스타일지향성은 지루함 성향 과 공적 자의식에 의해 $39 \%$ 의 설명력을 보였으나, 인터넷 패션제품 구매빈도는 스타일 지향성, 지루함 성향, 공적 자의식에 의해 $11 \%$ 의 설명력을 보였다. 스타일 지향성보다 인터넷 구매 빈도에 대한 낮은 설명력으로 인해 후속연구는 본 연구에서 포함한 지루함 성향, 공적 자의식 외 다양한 심리적 변수들 을 포함하여 구매빈도에 대한 설명력이 높은 모형 을 제시하여야 할 것이다. 또는 본 연구에서 포함한 스타일 지향성 외 다양한 패션관련 심리적 변수를 매개변수로 포함하여 설명력을 높일 수 있을 것이 다. 둘째, 지루함 성향을 측정하기 위하여 Farmer and Sundberg(1986)의 척도를 사용하여 요인분석을 실 시한 결과, 교차적재된 문항과 낮은 요인적재량을 보인 13 개 문항을 제외하고, 5 개 요인을 추출하였 다. 국내 소비자를 대상으로 지루함 성향 변수에 대
한 이해를 제시하는 연구가 없어서 본 연구의 요인분 석 결과와 비교, 논의가 불가능하였다. 따라서 후속 연구는 같은 척도를 이용하여 지루함 성향을 분석 한 후, 본 연구결과와 비교, 분석하여야 할 것이다. 더 나아가 성별에 따른 지루함 성향의 차이를 밝힌 선행연구들(Studak \& Workman, 2004; Vodanovich et al., 2011; Vodanovich \& Watt, 1999)과 같이 성별 에 따른 차이를 밝히는 것도 지루함에 대한 소비자 차이에 대한 이해를 제시할 수 있다. 또한 선행연구 들의 지루함 성향에 대한 요인분석의 다양한 결과는 연구대상에 따른 차이로 보인다고 분석한 Melton and Schulenberg(2009)에 의하면 연구대상에 따른 차이 가 예상된다. 따라서 연구대상에 따른 차이를 밝히 는 후속연구가 이루어지고, 이를 바탕으로 목표시장 에 따른 효과적인 전략을 수립이 가능할 것이다. 또 한 목표시장의 소비자 이해를 더 구체적으로 제시하 기 위해서는 연구대상에 따라 지루함 성향에 영향을 주는 변수들의 차이를 밝히는 후속연구도 필요하다. 셋째, 본 연구는 탐색적 요인분석에서 추출된 요인 모형이 다른 표본에서도 재현되는 정도를 검토하는 교차타당성분석을 제시하지 못하였다. 따라서 후속 연구는 대학생을 대상으로 제 2 표본을 수집하여 교 차타당성을 제시하여야 할 것이다. 넷째, 본 연구에 서 인터넷 쇼핑몰에서의 패션제품 구매빈도를 밝히 는데 있어서 패션제품을 의류, 가방, 액세서리를 포 함하는 광범위한 의미로 사용하여 빈도를 측정하였 으나, 패션제품들의 특성에 따라 소비자의 심리적 변수와 패션관련 심리적 변수의 영향이 다를 수도 있을 것이다. 따라서 후속연구는 패션제품의 종류에 따른 영향변수들의 차이를 밝히고, 제품 종류에 따 른 마케팅 전략을 차별적으로 제시할 수 있을 것이 다. 그리고 본 연구에서 인터넷 쇼핑몰에서 가장 최 근에 구매한 패션제품을 응답한 연구대상의 $71 \%$ 가 의류라고 한 결과는 대부분의 소비자가 의류제품에 가장 많이 구매한다는 것을 나타내므로, 후속연구는 의류제품만을 대상으로 하여 구매빈도에 영향을 주 는 변수들을 밝히는 것도 의미 있어 보인다.

\section{References}

Ahmed, S. M. S. (1990). Psychometric properties of 
the boredom proneness scale. Perceptual and Motor Skills, 71(3), 963-966. doi:10.2466/pms. 1990.71.3.963

Bae, B. R. (2011). AMOS 19 구조방정식 모델링: 원 리와 실제 [Structural equation modeling with Amos 19: Principles and practice]. Seoul: Chungram.

Bushman, B. J. (1993). What's in a name? The moderating role of public self-consciousness on the relation between brand label and brand preference. Journal of Applied Psychology, 78(5), 857-861. doi:10.1037/0021-9010.78.5.857

Casidy, R. (2012). An empirical investigation of the relationship between personality traits, prestige sensitivity, and fashion consciousness of Generation $\mathrm{Y}$ in Australia. Australasian Marketing Journal, 20(4), 242-249. doi:10.1016/j.ausmj.2012.05.012

Drory, A. (1982). Individual differences in boredom proneness and task effectiveness at work. Personnel Psychology, 35(1), 141-151. doi:10.1111/j.17446570.1982.tb02190.x

Farmer, R., \& Sundberg, N. D. (1986). Boredom proneness: The development and correlates of a new scale. Journal of Personality Assessment, 50(1), 4-17. doi:10.1207/s15327752jpa5001_2

Fenigstein, A., Scheier, M. F., \& Buss, A. H. (1975). Public and private self-consciousness: Assessment and theory. Journal of Consulting and Clinical Psychology, 43(4), 522-527. doi:10.1037/h0076760

Gana, K., Deletang, B., \& Metais, L. (2000). Is boredom proneness associated with introspectiveness? Social Behavior and Personality: an International Journal, 28(5), 499-504. doi.:10.2224/sbp.2000.28.5.499

Goldsmith, R. E., \& Hofacker, C. F. (1991). Measuring consumer innovativeness. Journal of the Academy of Marketing Science, 19(3), 209-221. doi:10.1007/ BF02726497

Gould, S. J., \& Barak, B. (1988). Public self-consciousness and consumption behavior. The Journal of Social Psychology, 128(3), 393-400. doi:10.1080/00224545. 1988.9713756
Gould, S. J., \& Stern, B. B. (1989). Gender schema and fashion consciousness. Psychology \& Marketing, 6(2), 129-145. doi:10.1002/mar.4220060205

Gutman, J., \& Mills, M. K. (1982). Fashion life style, self-concept, shopping orientation, and store patronage: An integrative analysis. Journal of Retailing, 58(2), 64-86.

Hong, B. S., Lee, E. J., \& Ma, H. Y. (2009). The effect of merchandise characteristics of Internet fashion shopping malls on the shopping values, purchase satisfaction, and repurchase intention of female consumers. Journal of the Korean Society of Clothing and Textiles, 33(1), 1828-1838. doi:10.5850/ JKSCT.2009.33.11.1828

Hong, K. H. (2010). A cross-cultural study on the influence of public self-consciousness and sociocultural pressure over ideal appearance attitude and body shame. Journal of the Korean Society of Clothing and Textiles, 34(10), 1731-1741. doi:10.5850/JKSCT.2010.34.10.1731

Hong, S. H., \& Lee, S. Y. (2014). The relationship between adult $\mathrm{ADHD}$ proneness and maladaptive behavioral anger responses: The mediating effects of external boredom proneness and perceived social support. Korean Journal of Counseling, 15(3), 1215-1233.

Hwang, J. S. (2003). The effect of clothing involvement and Internet usage on Internet shopping attitude and Internet purchase of clothing products. Journal of the Korean Society of Clothing and Textiles, 27(2), 177-187.

Jang, Y. H., \& Park, M. H. (2014). The influencing factors and the resulting factors of brand boredom. Journal of Consumption Culture, 17(4), 201-222.

Jeon, J. H., \& Yoo, T. S. (2011). Directional relationships of public self-consciousness and sociocultural attitudes toward appearance and objectified body consciousness on image management behaviors. Journal of the Korean Society of Clothing and Textiles, 35(11), 1333-1345. doi:10.5850/JKSCT. 2011.35.11.1333 
Ji, H. K. (2013a). The influences of shopping orientation and impulse buying orientation on Internet shopping addiction to fashion products. Journal of the Korea Fashion \& Costume Design Association, 15(2), 27-41.

Ji, H. K. (2013b). Characteristics of impulse buying according to price attitude towards internet apparel purchases: Focusing on the differences by gender and age. Journal of the Korean Society of Clothing and Textiles, 37(6), 737-749. doi:10.5850/JKSCT. 2013.37.6.737

Kim, G. S. (2001). AMOS 구조방정식 모형분석[AMOS structural equation modeling]. Seoul: Data Solution.

Kim, K. H. (2008). Study on the traits of college student-consumers by their lifestyle types, the images of Internet fashion shopping malls, and the purchasing behaviors. Fashion \& Textile Research Journal, 10(2), 198-208.

Kim, S. Y., Choi, S. Y., \& Kim. B. S. (2007). The impact of self-consciousness, stress, and Internet use control on Internet addiction among adults. Journal of Information Technology Services, 6(3), 47-67.

Klonsky, B. G., \& Dutton, D. L. (1990). Developmental antecedents of private self-consciousness, public self-consciousness and social anxiety. Genetic, Social \& General Psychology Monographs, 116(3), 275-297.

Koh, A. R., \& Kim, Y. J. (1996). The effects of egocentrism, self-consciousness, body cathexis on adolescence clothing behavior. Journal of the Korean Society of Clothing and Textiles, 20(4), 667-681.

Kwon, Y. H. (1997). Sex, sex-role, facial attractiveness, social self-esteem and interest in clothing. Perceptual and Motor Skills, 84(3), 899-907. doi:10. 2466/pms.1997.84.3.899

Lee, E. J., \& Kim, J. O. (2013). The effects of Internet fashion consumer characteristics, shopping motivation, and price sensitivity on negative purchasing behavior. Fashion \& Textile Research Journal, 15(3), 381-392. doi:10.5805/SFTI.2013.15.3.381
Lee, G. A., \& Hong, H. Y. (2013). The mediating effects of fear of negative and positive evaluation on the relation between public self-consciousness and social anxiety in university students. Korean Journal of Counseling, 14(4), 2271-2290.

Lee, H. J., \& Kim, S. M. (2006). A study on the determinants of impulse purchase of clothing products in the Internet shopping mall. The Research Journal of the Costume Culture, 14(6), 917-931.

Lee, O. H. (2008). Effect of interactivity and shopping value on relationship commitment and attitude toward the website. The Research Journal of the Costume Culture, 16(6), 1126-1141.

Lee, S. H. (2010a). Brand sensitivity and public selfconsciousness among fashion consumers. Journal of Fashion Business, 14(4), 102-110.

Lee, S. H. (2010b). Vanity, self-consciousness and brand consciousness. Journal of Fashion Business, 14(5), 93-101.

Lee, Y. J., Park, K. A., \& Heo, S. I. (2002). Attitude toward online stores: Differences by online shoppers' characteristics. Fashion \& Textile Research Journal, 4(5), 444-450.

Lim, J. Y. (2010). The proneness to boredom in the behavioral anger of male high school students: The effects of impulsiveness, sensational seeking, low frustration tolerance, and type A personalities. Studies on Korean Youth, 21(1), 67-89.

Lim, J. Y. (2014). Relationship between middle school boys' boredom proneness and game addiction: Focused on the mediation effects of impulsiveness. The Journal of the Korea Contents Association, 14(10), 610-618. doi:10.5392/JKCA.2014.14.10. 610

Lim, J. Y. (2015). Relationship between adolescents' internal and external boredom proneness and game addiction: Mediation effects of sensational seeking. The Journal of the Korea Contents Association, 15(5), 317-326. doi:10.5392/JKCA.2015.15.05.317

Mead, G. H. (1934). Mind, self and society: From the standpoint of a social behaviorist. Chicago: Uni- 
versity of Chicago Press.

Melton, A. M., \& Schulenberg, S. E. (2009). A confirmatory factor analysis of the Boredom Proneness Scale. The Journal of Psychology, 143(5), 493508. doi:10.3200/JRL.143.5.493-508

Miller, F. G., David, L. L., \& Rowold, K. L. (1982). Public self-consciousness, social anxiety, and attitudes toward the use of clothing. Home Economics Research Journal, 10(4), 363-368. doi:10.1177/ 1077727 X8201000407

Mittal, B., \& Balasubramanian, S. K. (1987). Testing the dimensionality of the self-consciousness scales. Journal of Personality Assessment, 51(1), 53-68. doi:10.1207/s15327752jpa5101_5

Na, Y. K., \& Suh, H. S. (2007). The effects of Internet shopping mall characteristics, consumer shopping propensity on perceived shopping values and satisfaction. Fashion \& Textile Research Journal, 9(6), 626-636.

Nirmala, R. P., \& Dewi, I. J. (2011). The effects of shopping orientations, consumer innovativeness, purchase experience, and gender on intention to shop for fashion products online. Gadjah Mada International Journal of Business, 13(1), 65-83.

Nystedt, L., \& Ljungberg, A. (2002). Facets of private and public self-consciousness: Construct and discriminant validity. European Journal of Personality, 16(2), 143-159. doi:10.1002/per.440

Park, E. H. (2015). Self-consciousness and make-up behavior according to attitude toward fast fashion typology of high school girls. Journal of Fashion Business, 19(1), 106-121. doi:10.12940/jfb.2015. 19.1.106

Park, E. J., \& Koh, S. B. (2008). Effects of internet shopping interest, shopping mall attribute, and emotions on impulse buying behavior for fashion products in Internet shopping mall. Journal of the Korean Society of Clothing and Textiles, 32(1), 1-11. doi:10.5850/JKSCT.2008.32.1.001

Park, H. J. (2013). Antecedents of dressing style. The Research Journal of the Costume Culture, 21(5),
639-654. doi:10.7741/rjcc.2013.21.5.639

Park, H. J. (2014). Role-relaxed consumption: Consumption related variables as antecedents and fashion consciousness as a consequence. The Research Journal of the Costume Culture, 22(3), 411-430. doi:10.7741/rjcc.2014.22.3.411

Park, M. H., Jang, Y. H., Lee, S. J. (2014). A literature review of 'brand boredom'. Yeungsang Journal, $7(1), 49-62$.

Park, M. J. (2008). The role of interactivity in online shopping environment. The Research Journal of the Costume Culture, 16(1), 145-157.

Rupp, D. E., \& Vodanovich, S. J. (1997). The role of boredom proneness in self-reported anger and aggression. Journal of Social Behavior and Personality, 12(4), 925-936.

Ryoo, H. H., \& Yoo, T. S. (2007). The relationship between self-consciousness and appearance management behavior of older women. Journal of the Korean Society of Costume, 57(9), 97-109.

Seib, H. M., \& Vodanovich, S. J. (1998). Cognitive correlates of boredom proneness: The role of private self-consciousness and absorption. The Journal of Psychology, 132(6), 642-652. doi:10. 1080/00223989809599295

Son, E. J. (2007). The influence of public self-consciousness, the internationalization of sociocultural value and the attitude of body image on the intention of plastic surgery. The Korean Journal of Woman Psychology, 12(1), 63-81.

Son, E. J. (2008). The influence of self-esteem, physical comparison, thin-ideal internalization, and body dissatisfaction on the eating disorder symptoms of college aged women. The Korean Journal of Counseling and Psychotherapy, 20(3), 885-901.

Son, T. D. (2014). A dangerous play: Anatomy of "boredom" and its impacts on adolescence identity formation. A Journal of Christian Education in Korea, 38, 85-119.

Studak, C. M., \& Workman, J. E. (2004). Fashion groups, gender, and boredom proneness. International 
Journal of Consumer Studies, 28(1), 66-74. doi: 10.1111/j.1470-6431.2004.00335.x

Vodanovich, S. J., \& Kass, S. J. (1990). A factor analytic study of the boredom proneness scale. Journal of Personality Assessment, 55(1/2), 115123. doi:10.1080/00223891.1990.9674051

Vodanovich, S. J., \& Watt, J. D. (1999). The relationship between time structure and boredom proneness: An investigation within two cultures. The Journal of Social Psychology, 139(2), 143-152. doi:10.1080/00224549909598368

Vodanovich, S. J., Kass, S. J., Andrasik, F., Gerber, W. D., Niederberger, U., \& Breaux, C. (2011). Culture and gender differences in boredom proneness. North American Journal of Psychology, 13(2), 221-230.

Vodanovich, S. J., Wallace, J. C., \& Kass, S. J. (2005). A confirmatory approach to the factor structure of the Boredom Proneness Scale: Evidence for a two-factor short form. Journal of Personality Assessment, 85(3), 295-303. doi:10.1207/s15327 752jpa8503_05

Vodanovich, S. J., Watt, J. D., \& Piotrowski, C. (1997). Boredom proneness in African-American college students: A factor analytic perspective. Education, 118(2), 229-236.

Von Gemmingen, M. J., Sullivan, B. F., \& Pomerantz, A. M. (2003). Investigating the relationships between boredom proneness, paranoia, and self-consciousness. Personality \& Individual Differences, 34(6), 907-919. doi:10.1016/S0191-8869(01)00219-7
Wan, F., Youn, S., \& Fang, T. (2001). Passionate surfers in image-driven consumer culture: Fashion-conscious, appearance-savvy people and their way of life. Advances in Consumer Research, 28(1), 266-274.

Watt, J. D., \& Hargis, M. B. (2010). Boredom proneness: Its relationship with subjective underemployment, perceived organizational support, and job performance. Journal of Business and Psychology, 25(1), 163-174. doi:10.1007/s10869-009-9138-9

Watt, J. D., \& Vodanovich, S. J. (1992). Relationship between boredom proness and impulsivity. Psychological Reports, 70(3), 688-690. doi:10.2466/ pr0.1992.70.3.688

Watt, J. D., \& Vodanovich, S. J. (1999). Boredom proneness and psychosocial development. The Journal of Psychology, 133(3), 303-314. doi:10. 1080/00223989909599743

Wells, W. D., \& Tigert, D. J. (1971). Activities, interests, and opinions. Journal of Advertising Research, 11(4), 27-35.

Workman, J. E., \& Lee, S. H. (2011). Vanity and public self-consciousness: A comparison of fashion consumer groups and gender. International Journal of Consumer Studies, 35(3), 307-315. doi:10.1111/ j.1470-6431.2010.00934.x

Workman, J. E., \& Studak, C. M. (2005). Relationships among fashion consumer groups, locus of control, boredom proneness, boredom coping and intrinsic enjoyment. International Journal of Consumer Studies, 31(1), 66-75. doi:10.1111/j.14706431.2005.00486.x 